\title{
Del ángel al andrógino: fantasías y deseos en El bautismo de César Aira
}

\author{
Gilberto D. VÁsquez Rodríguez
}

Y por mano del Ángel subió delante de Dios la humareda de los perfumes... (El libro del Apocalipsis)

\section{Resumen:}

El perfil andrógino del ángel aparece en diversas teosofías y estéticas. Esta característica ha sido vista como una promesa de la recomposición final, ontológica de los seres. Pero desde esta perspectiva, el ángel será conducido y conductor del espacio de los deseos y las latencias y en la literatura será el medio para expresar una retórica del deseo, una sublimación de lo divino en la belleza ambigua. El presente trabajo desarrolla esta idea teniendo como centro la novela de César Aira, El bautismo (1991). En esta obra se articula la promesa andrógina desde las heterogeneidades de los discursos sobre lo angelical, no precisamente con intención de prescribir una legitimidad o una contralegitimidad (lo demoníaco) sino ofreciendo una visión androgínica que cuestiona y revierte la imagen imposible desde la discordancia de la temporalidad del deseo y el desalojo de las esencias.

Palabras clave:

Andrógino, El bautizo, César Aira, ángeles en literatura, deseo en literatura.

* Universidad de Murcia. 
La estética angelical confluye desde el amplio espectro de las representaciones hasta una de sus vertientes androgínicas más señaladas: la de la plenitud ambivalente, que se levanta eufóricamente por una concepción del Bien y la Belleza y se expresa en términos de juventud eterna, de felicidad sublime. El ángel investido de un conocimiento superior, ${ }^{1}$ habitante del territorio de Dios, nos ha revelado la felicidad trascendente de una armonía de los sexos, de una supersexualidad, autárquica o, contrariamente, una anulación, una tachadura, el latido de una neutralidad imposible, atributo de su asexualidad. Ese cuerpo celestial asciende con una naturaleza superior, desde la indistinción, activando el deseo de lo otro, pues se ve ahí, en su imaginería, como sustraído de la vicisitudes de la sexuación, de la separación del humano ser.

El perfil androgínico del ángel resurge en diversas teosofías y estéticas, ${ }^{2}$ por esa extraña, a la vez que impactante fusión, yuxtaposición de formas masculinas y femeninas. La estética euforizante lo ha tomado para sí como cifra de una promesa de recomposición final, pues la aspiración romántica del devenir ángel no es más que la escatología en la que, según la alteridad de los sexos, se ha marcado una división ontológica de los seres. El ángel en esta reiteración será conducido al espacio de los deseos y las latencias, de las aspiraciones y los fetiches y también será apropiado por la literatura

${ }^{1}$ En este sentido Inmanuel Swedenborg sentencia que: "La sabiduría angélica sobrepasa a la humana en tal magnitud que resulta desde todo punto de vista inefable, y lo mismo puede decirse de todo lo relacionado con los ángeles. Las vestiduras con las que los ángeles se visten tienen cierta correlación con todas las cosas celestiales. Sus ropas están en correspondencia con su intelecto y por tanto puede saberse la inteligencia de cada uno de los habitantes del cielo viendo cual es la calidad de sus ropajes [...]. Los que habitan en lo recóndito del Cielo, están desnudos, pues han sido llevados allí en un estado de inocencia y la correspondencia de ésta es la desnudez" (147-148).

${ }^{2}$ Las teorías místicas de Inmanuel Swedenborg sitúan una otredad de los ángeles, una trascendencia de la belleza en el territorio celeste, lugar que aglutina en el infinito todas las posibilidades del ser en la armonía y la plenitud. Esa distinción, ese esplendor y esa belleza irresistible del ángel tendrán su apogeo en las formas andróginas que nos presenta Balzac o enmarañadas en la pintura decadentista, como en los lienzos de Gustave Moreau. 
para expresar de muy diversos modos una retórica del deseo, una sublimación de lo divino en la belleza ambigua.

La novela del prolífico escritor César Aira, ${ }^{3}$ El bautismo (1991), se articula desde distintos signos, desde las heterogeneidades de los discursos sobre lo angelical, no precisamente con intención de prescribir una legitimidad de la promesa andrógina o de un devenir androgínico, ni tampoco con una mirada euforizante, ni mucho menos desde el anatema teológico e imaginario contrario, la del ángel investido de lo demoníaco.

La agudeza estética que establece El bautismo radicaría en otra visión androgínica, la que cuestiona y revierte desde la imagen imposible, desde el estilo disonante en la temporalidad del deseo, la fluctuación de lo monolítico o el desalojo de las esencias, pues como veremos en esta novela, el personaje -el ángel ${ }^{4}$ - no deja de responder a la forma varonil más o menos consensuada, es decir nadie diría que, a pesar de su forma androgínica/angelical, copie o imite a la mijer, ni desee reemplazarla en sus deseos del sexo contrario. Veremos que en el contorno de la mirada, como podrá notarse también en la novela Ave roc de Roberto Echavarren, el ángel no anula

${ }^{3}$ César Aira (Coronel Pringles, Argentina, 1949) ha publicado, hasta la fecha, una gran cantidad novelas, entre las que destacan: Moreira (1975), Ema, la cantiva (1981), La luz argentina (1983), Las ovejas (1984), Canto castrato (1984), Una novela china (1987), Los fantasmas (1990), El bautismo (1991), La liebre (1991), Embalse (1992), El Ilanto (1992), La Prueba(1992), El volante; La guerra de los gimnasios (1992), Madre e bijo (1993) y el Diario de la hepatitis (1993), Cómo me hice monja (1993), Los misterios de Rosario (1994), La costurera y el viento (1994), El infinito (1994), Los dos payasos (1995), La abeja, (1996), La trompeta de mimbre (1998), La serpiente (1998), El sueño (1998), Las curas milagrosas del Dr. Aria (1998), La mendiga (1998), Congreso de literatura (1999), El mago (1999), Un episodio en la vida de un pintor viajero (2000). Tres cuentos: "El vestido rosa", "Cecil Taylor y "El infinito. Cuatro libros de Ensayo: Copi (1991), Nouvelles impressions du Petit Maroc (1991), Taxol: precedido de Duchamp en México (1997), Alejandra Pizarnik (1998) (Ver Quintero 81-89).

${ }^{4}$ En la dramaturgia hispanoamericana, la figuración del ángel tiene una resonancia fundamental como correlato bíblico con Los ángeles terribles (1966) de Román Chalbaud. Los personajes de esta obra, eco de los arcángeles bíblicos, Miguel y Gabriel, están escindidos de una totalidad que los diluye en un solo cuerpo celestial. En la escena (obertura de la obra), repiten de forma mítica el coito entre los ángeles, que 
la diferencia de los sexos, ni los fusiona..$^{5 *} \mathrm{La}$ apariencia obra una fluctuación, un límite del deseo que la percepción encapsula en la mirada deseante, en el fetiche. El personaje angelical, a través de la mirada, como advierte el mismo Echavarren, ${ }^{6}$ no es un disfraz, "es una sucesión vertiginosa de disfraces" ${ }^{\text {"7 }}$ que crea una vibración sobre la que no se puede decidir.

Tal vibración absorben las "ideas" del disfraz, de los enmascaramientos, pero también de lo monstruoso y de lo indefinido y se insertan en los múltiples bordes que conforman la historia en la obra de Aira. Los indicios espaciales y temporales de la novela, ubican esa historia en el campo de la pampa argentina, en un caserío llamado "El pensamiento", probablemente en los años treinta.

enuncia aún más su separación humanizada. Esto generará un drama de tipo ritual, un juego de máscaras y sustituciones, un vaivén de identidades. Mientras Gabriel permanece asido simbólicamente a la cama y no puede salir de ese espacio, Miguel, que es todo exterioridad desafiante y chulesca, conforma lo otro. Estos personajes se encuentran despojados de cualquier poder celestial y condenados a una marginalidad abismante. Fueron recogidos por un mendigo hacedor de muñecas grotescas, Zacarías (el profeta), que puebla su universo de sexos de tela y relleno, con fantasmas de muñecas gordas colgadas del techo. Al tiempo, Sagrario se aventura embarazada de cualquiera de los tres o de los tres a la vez, surgiendo de allí motivos larvarios en torno a la androginia. "SAGRARIO -(viendo a Gabriel): Es increíble como Gabriel ha crecido. Muy rápido. Hace pocos años era un niño ¡Cómo ha crecido de rápido! No es un hombre, pero tiene algo mejor que un hombre. Ahora tiene lo mejor de la mujer y lo mejor del hombre. Lo lleva consigo. Adentro y afuera...” (12).

${ }^{5}$ Compárese este planteamiento con los formulados en la ensoñación de la novela de Manuel Puig, Pubis angelical: "De pronto se desató un viento extraño y el camisón se alzó, mostrándome desnuda, y los hombres temblaron, y es que vieron que yo era una criatura divina, mi pubis era como el de los ángeles, sin vello y sin sexo, liso. Los guerreros se paralizaron de estupor. Un ángel había descendido sobre la tierra” (266).

${ }^{6}$ Haremos referencia al apartado que este autor le dedica en su ensayo a la novela de Aira (Ver Echavarren, "El ángel fuera de la iglesia" 160-169).

${ }^{7}$ La ensoñación del ángel como sujeto henchido de ambigüedad y salvación, como forma que se oculta y que se muestra metamorfoseándose, la podemos apreciar también en la novela de Reinaldo Arenas, Arturo, la estrella más brillante. Él, el ángel, es el resuello de los misterios divinos y terrenales, la puerta de acceso a un 
La novela tiene dos partes. En ambas, la intervención tenaz de los elementos naturales condiciona el ritmo de lo narrado, pues tanto en la primera como en segunda, la historia, los personajes y la narración misma, diríamos incluso, el proceso narrativo, parecen destinados a responder al ritmo de las fuerzas telúricas, al arrase natural, concatenado a lo vertiginoso de las ideas. El temporal de viento activará la narración de la primera parte, y la inundación que sumergirá a los personajes en una lucha contra el arrase de lo acuoso, será el centro de la narrativa en la segunda.

Así pues, al inicio de la novela un viento atroz arrastra un pequeño animal sustraído de sexuación y de especie, un animalito subterráneo expulsado del interior de la tierra por las agitaciones conjeturadas de un toro tectónico. La narración se detiene en detalles y reflexiones que salen de un acortamiento, suponemos, de la percepción narrativa en torno al objeto que se atisba, en este caso el pequeño bicho. El animal, que danza en el cuerpo del viento furioso, va asimilando, impugnando y reflexionando esa donación abrupta que la naturaleza le ha dado, de forma súbita, en un vuelo sin dominio de esa capacidad, como una especie de habilidad impuesta. El narrador introduce una estrategia del límite en la figuración de la bestezuela, pues no sólo carece de un sexo determinado, o reúne los dos, sino que también contrapone en mismo cuerpo lo salvaje y lo humano, lo sagrado y lo inteligible, la imagen y el concepto. La ambivalencia del animal sumido en vibración del vendaval nos otorgará por un lado el rumor filosófico que conlleva toda

espacio de acogida. “...qué suena así, tan increíble más allá de las piedras? son las verdes aguas, las perfumadas, las ceremoniosas, las gloriosas aguas que se abren para que él penetre, para que tú y él se encuentren y finalmente les otorguen su verdadera definición... y Arturo oyó aquel rumor reciente, aquel ritmo, el suave trepidar de todos los seres, y hasta las cosas, que de algún modo se comunicaban con él y le anunciaban, entusiasmadas, que él, el divino, venía, se acercaba...” (85). Cursivas del autor. 
dualidad, además de un signo de predestinación que asume este motivo en la novela.

Pues bien, el animalito se dijo en su balbuceo mental, que ya que la suerte estaba echada, le convendría obtener algo de placer de esta experiencia, que será la última suya. ¡Debería disfrutar el vuelo! Por lo pronto, nunca había volado antes [...]. Sería agradable hacerlo, en efecto, imitar a los pájaros, más todavía sin ser miembro del género alado. (Aira 9) ${ }^{8}$

El signo del animal que no es pájaro y que, sin embargo, vuela por designio de ¿alguien?, de la fuerza natural, reflexiona agitado en su arriesgada y definitiva realidad, señalando un contorno temerario donde lo incierto toma el cariz de una sutileza que invadirá el talante de la narración. El bicho niega lo determinado, la certeza, con lo cual se introduce en el territorio de lo conjetural y tentativo, se ve avivado por la verdad de su desastre, pero más aún por el rumor de lo inabarcable, la intuición de lo indecible. Una especie de danza nietzscheana recorre estas páginas demoradas en la bestia que marca la sucesión, el movimiento o desplazamiento hacia lo que está por suceder en la novela: el vértigo de lo inesperado, pero paradójicamente previsto. La danza nietzscheana sobre el filo de la navaja, sobre el movimiento que entraña otro saber desde lo ambiguo, como capacidad cognoscitiva.

Mientras el bicho revolotea (y reflexiona), a punto de morir, estrellado primero contra el personaje y luego contra el suelo, en esa noche temible y cerrada, oscura y demencial, en la que el vasco Mariezcurrena, vecino de aquel pueblo aislado en la pampa argentina, toca la puerta de la casa del cura. Una visita a esas horas y con aquel vendaval sólo podría tratarse, en las lucubraciones del sacerdote, de la muerte de alguien: probablemente de la vieja, de la mujer del vasco. El cura lo hace entrar a la casa y allí, las especulaciones

\footnotetext{
${ }^{8}$ Las cursivas que se utilicen en las citas de esta novela son nuestras, salvo en los casos especificados.
} 
más rocambolescas por parte del sacerdote se disipan cuando el vasco, después de un rodeo característico asegura que:

Dios nos ha bendecido, a mi querida señora y a mí, con un retoño, pero a medias. Tememos por la integridad de la bendición, señor padre, y a ese temor se debe esta visita con la que temo molestarlo [...]. Ha sido un caso de urgencia y si he venido ha sido nada más que por catolicismo, a pesar de la inclemencia (Aira 17-18).

El cura piensa en un principio que se trata de una consulta de adopción de un niño y luego de un desvarío de un padre atolondrado o culpabilizado por la suerte de uno de sus ya crecidos hijos. Pero el vasco aclara: "Mi señora ha dado a luz justamente en esta noche inclemente". El cura se manifiesta aturdido y estupefacto por la noticia, pues repitiendo el milagro bíblico, el vasco y su mujer, personas de avanzada edad, conciben una criatura: “... ¿ ¿pero su señora no es de edad algo madura, o sea avanzada excesivamente para la procreación?” (Aira 9). ${ }^{9} \mathrm{El}$ vasco aclara que su mujer, a pesar de ser anciana, aún está en posesión de la fertilidad, pero que el destino ha querido que ese hijo, el último de siete, naciera sietemesino, incompleto, prematuro, adoleciendo todavía del vientre materno: "Ya por ser prematuro, ya por haber sido concebido, como usted manifestó, a una edad relativamente avanzada, ya porque mi señora no se ha estado sintiendo bien últimamente, la criatura ha resultado bastante débil y poco vital. Tememos que no perdure. Querríamos que nos lo bautice mientras hay tiempo" (Aira 18).

El sacerdote, a pesar de estar convencido de que la criatura morirá (pues ese nacimiento, tendría, se dice para sí mismo, algo de luctuoso en ciernes), accede a trasladarse hasta la casa del vasco y bautizar a aquella criatura prematura. Y ya fuera, rumbo hacia la casa,

${ }^{9}$ Sabemos que la imagen de la anciana embarazada, según la estética dialógica que propone Bajtin de ese símbolo de lo carnavalesco, implica una lectura que unifica en mismo cuerpo la no-separación de vida-muerte, pues la vejez más cercana a la muerte se ve regenerada por el advenimiento del nuevo ser (ver Bajtin 43-78). 
montados en un antiguo carromato de campo, extraviados en la oscuridad y el viento, un bicho que revoloteaba en la ventisca se estrella contra la espalda del vasco, rebotando en el camino a una distancia más o menos perceptible al frente de ellos. El bicho, carente de nombre y de sexo, queda atolondrado por el golpe en el camino y el vasco de una manera rocambolesca, luchando contra el viento, lo captura, lo reconoce y lo nombra. ${ }^{10}$

Ese reconocimiento del animal que, como dijimos al principio, se hallaba metido en una suerte de indeterminación, unido a la identificación de su posible sexo ("tiene un pitín alargado"), lo sitúa ahora en el espacio cierto de las determinaciones con lo que el nombre y el atributo sexual no serán una causa, pero sí un signo considerable, cuando el vasco ya en casa, dice: "Lo voy a carnear". Una vez llegados a la casa, el cura y el vasco se presentan ante la recién parida. Todos parecen eludir el motivo de la búsqueda y visita forzada del cura, retrasan la acción definitiva de la presentación del niño ante los ojos del sacerdote y la acción misma del bautismo. Por fin, la mujer del vasco le explica ceremoniosa la necesidad del bautismo para su hijo recién nacido, con probabilidades, de que muera y antes de eso, ha preferido hacerlo llegar a la casa para "purificar"11 el cuerpo de la nueva criatura. El sacerdote se muestra suspicaz porque son muchos los detalles nimios en los que depara la pareja, lo fundamental parece agazapado en la inquietud y en lo supuesto.

10 “Qué pasa, por Dios”, exclamó el acompañante. “¿Un piche!” [...] Era un tatú pequeñito, de los que caían de los bordes del campo a las colchonetas de polvo yermo de la calle, y perdían días de ayuno hasta que conseguían volver a subir; no lo conseguía nunca porque los atrapaba algún chacarero" (Aira 28).

${ }^{11}$ Para Mircea Eliade la inmersión como su resonancia en el significado simbólico del bautismo comporta la capacidad de purificación, pues el poder de lo acuoso se alberga en la totalidad, en que todo lo contiene, sin separaciones y todo lo desintegra. La historia individual y anterior de los seres inmersos en el agua, queda, a todas luces, cancelada, pues la inmersión equivale en el plano humano a la muerte y en el plano cósmico a la catástrofe que sume al mundo en los ciclos habituales y periódicos del universo. La inmersión, la vuelta a las aguas, plantea una regresión a la totalidad fundante, primordial y poder se encarna en el símbolo como regeneración (Ver Eliade 200-226). 
"No sabemos todavía qué nombre ponerle". El cura se desconcertó, no había pensado en ese necio inconveniente [...] "No tiene tanta importancia", atinó a decir, "el nombre es secundario en el bautismo. Pero necesario dentro de todo". “¿Rosario?”, propuso tímidamente la madre, restregándose las manos con nerviosismo. El cura pensó de inmediato en Cavallaro, un matrimonio italiano de Lartigau que ostentaba la curiosa propiedad de llamarse, marido y mujer, 12 igual: Rosario. La propuesta no tuvo la aprobación del chacarero, que hizo un gesto de impaciencia y preguntó: "¿Pero se puede bautizar y dejar el nombre en suspenso?” [...] -el sacerdoterepitió: "El nombre no tiene tanta importancia, sólo la tiene para hacer completo el bautismo. Los sacramentos no son requisitos legales, ni equivalen a tales; son los momentos que establecen la inocencia del cristiano respecto de la doctrina. Pero si insisten", terminó, "puedo bautizarlo sin nombre, como un desconocido”. (57)

La intriga del cura por la montaña de escrúpulos que levantaban ante él, le hacen sospechar una reserva, algo oculto, que no termina de decirse. La conversación resulta entonces un tanto hilarante. El matrimonio de ancianos intuye que el sacramento del bautismo es un acto de bendición y purificación cuyo resorte es lo nominativo, de allí la sentencia: "En el nombre del Padre, del Hijo y del Espíritu Santo, yo te bautizo con el nombre de..." pues, como estudia Mircea Eliade, el bautismo, ${ }^{13}$ cuyo sentido y propiedad fundamental lo ad-

${ }^{12}$ Cobra resonancia en este sentido la concepción de la gemelidad, la dualidad y la pareja saciados con respecto a los estados androgínicos.

13 “Ese simbolismo fundamental y ecuménico de la inmersión en el agua como instrumento de purificación y regeneración fue adoptado por el cristianismo y se enriqueció con nuevas valencias religiosas. El bautismo de san Juan buscaba ya no la curación de enfermedades corporales, sino la redención del alma, el perdón de los pecados. Juan Bautista predicaba 'el bautismo de arrepentimiento para la remisión de los pecados' (Lc. 3:3), y añadía: 'Os bautizo con agua, pero aquél que es más fuerte que yo los bautizará con el Espíritu Santo y el fuego’ (Lc. 3:16). En el cristianismo el bautismo se convierte en el principal instrumento de regeneración, porque la inmer- 
quiere el cristianismo con la articulación previsible de otras tradiciones, se entabla como una invocación de regeneración espiritual: se muere simbólicamente y se emerge renovado de las aguas, resucitado en la fe, de allí la frase del Ezequiel 36: 25, "os rociaré con aguas puras y seréis puros". El nombre de Rosario, para mujeres y hombres, sugiere entonces la forma incierta, y no dicha, que tiene la criatura en cuanto a su determinación en un sexo u otro.

El matrimonio conduce al sacerdote hasta la habitación donde está el moisés que contiene la débil respiración del niño. A pesar de que todo el rodeo se hizo con la intención de preparar al cura para el espectáculo de la fealdad y de la fragilidad del sietemesino, una sorpresa horripilante se suma a otra:

¿Qué diablos era eso? No podía sacarle la vista de encima, atontado. Para completar la madre desdobló la funda de la almohada, y le mostró el cuerpo, quizás con la inocente esperanza de convencer al sacerdote con formas algo más humanas, o al menos no pasar por tanta vergüenza. Esperanza condenada de antemano al peor fracaso. Brazos y piernas eran cuatro patitas del espesor de líneas, dobladas de cualquier forma y desmayadas. La única redención, y modestísima, estaba en los pies, que eran dos grandes patas de rana grises, con el dedo gordo (pero éstos eran flaquísimos) más o menos formado; los otros no. El otro era desmesurado, dentro de la escasez de todo, como inflado y violentamente corrido para un costado. (60)

Más adelante, en la misma página, continúa el narrador, diciendo que la fealdad, la monstruosidad de la criatura, tal como lo describe, no era lo peor, pues: "de pronto, y se explicó las vacilaciones

sión en el agua equivale a la muerte y resurrección de Cristo. "¿Ignoráis - escribe san Pablo- que todos nosotros que hemos sido bautizados en Jesucristo, hemos sido bautizados en su muerte? (Rom. 6:3)" (Eliade 207). 
por el nombre. Sabía, El cura lo presintió porque se lo habían dicho, que lo más impresionante en los recién nacidos era el sexo, por desmesurado y ruin a la vez. El de este ser debía ser una fatalidad. No sabía que esperar".

El presentimiento se confirma cuando, por fin, al quitar las vendas y los pañales que ocultan el sexo de la criatura:

El cura tuvo la desalentadora oportunidad de contemplar un sexo que tanto podía ser femenino como masculino. Su primer impulso fue decirse, como es natural: "Era hembra". Sin embargo, también es natural lo contrario. Eran suposiciones que no se implicaban. Lo propio de ese ser que de repente, a sus ojos, habia perdido las propiedades necesarias para que se hablara naturalmente de él, era indiscernible, un revoltijo que valía no mirar con atención (ya lo había hecho). ¿María?, ¿Cristo? Ahí estaba el meollo. Sin decir media palabra se dio media vuelta y enfiló para la puerta. (61)

La criatura, aparte de monstruosa o por esa misma razón, era sexualmente indiscernible, estaba al margen de la definición de los sexos, teniendo la injerencia de retraer la figuración del hermafrodita en los supuestos de una involución del ser o de una falta de maduración. De este modo, el cura se niega a bautizar a una criatura que aún no está definida, con lo cual no puede ser nombrada con un nombre propio en un sexo o en otro, pese a que el sacerdote restaba importancia a la elección del nombre. El cura alega, en su negativa al bautismo, y sin nombrarlo directamente, el estamento médico, jurídico-religioso e incluso ético del anatema contra los hermafroditas: la indefinición. ${ }^{14}$

\footnotetext{
${ }^{14}$ Revísese de manera general las ideas vertebrales que, según Michel Foucault, se contienen en "lo monstruoso", y de una manera singularizada lo relacionado con el repudio del hermafrodita. Este autor analiza cómo el hermafrodita trastoca las leyes "naturales" en la división de los sexos y las leyes humanas, edificando en su falta de discernimiento sobre su "verdadera y natural" identidad el cuestionamiento del requisito esencialista de la identidad unívoca, requisito sine qua non para el desempeño
} 
El vasco: “¿Cómo define usted la indefinición?” El cura (retrocediendo otro paso, ya que estaba a varios millones de pasos, metafóricamente, por supuesto, porque seguía sentado): "No se puede hacer entrar lo indefinido en el campo de lo definido, o de otro modo perderíamos el pensamiento" [...]. ¿Acaso tiene miedo de que resulte un gato, un murciélago, un canguro?", preguntó el vasco. El cura aspiró hondo: “Y qué tendría de malo que lo temiera? La función del bautismo es justamente la preservación de lo bumano como bumano, por acción de los símbolos. En ese campo, toda precaución es poca. Para decirlo de otro modo: en algún momento debí optar entre equivocarme siempre, o no equivocarme nunca. No sé cuál de las dos opciones elegí, pero sé que fue una, y sólo una de ellas, la que se volvió mi único camino posible. (62-63)

Como representante de la Iglesia, el cura, sin duda, centra en el más puro orden dogmático, las nociones de la determinación, lo definido y lo definible y la verdad de las cosas. En una palabra, estaría negando la posibilidad de lo incierto, pues la justeza de todo pensamiento teñido de racionalidades y conceptos o dogmas, imantados por el logos, se separa de lo irracional, de lo indeterminado. De alguna manera, como señala el filósofo Armando Rojas Guardia, el sacerdote ubicado de lado de certezas y de lo evidente, le teme a lo incierto, ${ }^{15}$ a esa liminaridad. El cura no puede arriesgarse a bautizar una criatura sin una identidad natural evidente y determinada, pues estaría contradiciendo el principio y el camino -elegido - de la verdad, la certeza y lo verificable unido a las formas

de los roles, apariencias y formas asignados a los sexos, la garantía de la procreación y la continuidad de las generaciones (Ver "Les anormaux").

15 "Solemos temerle a la incertidumbre. Preferimos aferrarnos, sin más, a una ley abstracta, a una mecánica repetitiva de hábitos, al aura vaga que desprenden ciertas palabras consagradas, a un afecto que empobrecemos por manosearlo sin cesar, al rol que desempeñamos frente a los otros, a la imagen o idea que tenemos de nosotros mismos, a una circunscrita, hogareña postura ante la realidad. La incertidumbre nos 
coercitivas e irracionales -inexplicables- del rito. Era muy probable que la criatura muriera, pero ¿y si no?, ¿y si la distinción no insta a la separación o a maduración distintiva de los sexos que se yuxtaponen en el recién nacido? De ser así, el cura estaría promoviendo la inserción de la anomalía, de la indefinición en lo cotidiano y en Dogma. El bautismo resuena, desde lo simbólico, la nominación y la determinación, en las convenciones del pacto social y político ${ }^{16}$ donde cada ser se insertará. En caso de que la criatura recién nacida sobreviva, el bautismo no podría bendecir el equívoco.

La madre vuelve a proponer que sea bautizado con el nombre de Rosario, que es tanto para varones como para hembras, logrando, si muere, que la criatura no decaiga en el limbo. El cura se niega, pues el recién nacido pertenece al territorio del acertijo. Para él, el niño/ niña es una adivinanza cuya respuesta, la determinación sexual, se sabrá con el tiempo. Sólo entonces será posible la ejecución del bautismo. El matrimonio insiste en el sacramento apostando, conjeturando que su criatura no puede ser sino un varón. El cura no dice nada. Y hacia el final de esta primera parte, el sacerdote que-

pone a caminar, súbitamente en ocasiones, sobre la cuerda suspendida en el vacío [...] La incertidumbre nos lanza a caminar sobre la cuerda floja. Y este es su primer aporte epistemológico. Lo real se patentiza, entonces riesgoso. En el ámbito ubicuo de la incertidumbre se nos radicaliza hasta el extremo a menudo insoportable la naturaleza peligrosa de la realidad. Por la grieta inesperada de una convicción o de una serie de convicciones, calándonos, el viento frío, liberador, del vértigo; liberador porque todo lo que constituía solidez cognoscitiva se desmorona y pulveriza hasta fluir, es decir, hasta moverse. Henos en el lugar del desplazamiento" (27 y 29).

${ }^{16}$ Recordemos que, como ha advertido Michel Foucault, en los períodos que abarca entre la Edad Media y el siglo XVII, la medicina y el derecho canónico y civil, se había reconocido la existencia de dos sexos naturales: femenino y masculino y un tercer sexo aberrante: el hermafrodita. Desde los tribunales de justicia hasta la mirada legitimada del médico, se insistió en los casos de aberración sobre la elección, en principio por los padres o tutores o padrinos, de un solo sexo natural, para que éste quedara fijado en forma de identidad a partir del sacramento de bautismo. Pero a partir del siglo XVIII, señala Francisco Vázquez, "Corresponderá al médico desde entonces decidir, más allá de las preferencias del sujeto o de sus parientes, cuál es el verdadero sexo de los casos de duda" (218). 
dándose en la casa, en vista de lo arreciado del vendaval, atiende a la mujer del vasco quien saca una revista, Campo argentino, mostrándole un cuento ilustrado, una novela-folletín, que será un factor, como dice Echavarre (Arte Andrógino 161), coactivo o de correlato. ${ }^{1{ }^{\circ}}$ Folletín que está en relación con el enigma del sexo de la criatura. Durante la velada, el cuento es leído en voz alta por el cura (quien antes por sugerencia de la mujer y del vasco se detuvo en las ilustraciones bastas y de "plumazos rápidos") agradeciendo que esa literatura no fuera un evangelio o algún tipo de narración edificante.

La trama del cuento insertada en la novela es la siguiente: un viejo de la pampa argentina vive con sus siete hijos jóvenes. Y un matrero disfrazado oficial se acerca a su casa. El viejo teme que este pícaro, este fraudulento oficial, se lleve a sus hijos a la milicia, para la lucha contra los indios. Previendo esto, les ordena que se disfracen de mujer, sustrayendo barbas e indicios masculinos. La afeitada deja marcas en el rostro, pero aún así parecen frondosas muchachas de campo. El oficial induce al viejo a tomar licor y tras la conversación amenizada por la ebriedad, le sugiere al viejo que le "done" alguna de sus "hijas" para desahogarse sexualmente. El viejo se niega y el falso oficial le atraviesa con su sable, esconde el cadáver debajo de unos cueros y seguidamente intenta violar a cada una de "las hijas" del viejo. Las primeras seis se niegan y son atravesadas y cortadas por su sable en una seguida y cruenta carnicería. Pero "la última", de quince años, la más "bonita", de brazos regordetes y de formas renacentistas, es "atrapada" y acorralada, y

${ }^{17}$ Para Sandra Contreras, César Aira retorna al extremo de lo novelesco, a la raíz de la anécdota "capta el relato en lo su elemento diferencial, es decir aquello que lo hace nacer al mundo, ya, repitiendo". Esto conlleva por consiguiente una vuelta al relato, una recuperación de la historia en estado puro, se articula desde un correlato o relato primordial (los símbolos del imaginario: la lectura de la leyenda del lobizón). Dice la misma autora: "Si la literatura de Aira, vuelve, hoy, al relato es porque implica, cada vez, la extracción, de ese relato en sí que siempre "había estado antes”, por lo demás es lo único que hace falta para que el mundo empiece [...]. Si la ficción es aquí condición del comienzo es porque se afirma como la emergencia instantánea de la fábula en su forma más singular, insustituible” (107). 
al levantar sus faldas para consumar el acto, surge un horripilante lobizón:

Pero la risa se le congeló en los labios cuando vio, muy cerca de él, y muy claro porque ahí daba el pleno fulgor de la luna, un torbellino de movimiento, y había tenido apenas tiempo de reconocer el vestido floreado de la chinita que perseguía, cuando de sus ruedos salía feroz y como mojado de un rocío fosforescente un gran lobo negro, con los ojos brillantes como dos carbones, los dientes al aire, y saltaba hacia él como un gruñido que helaba la sangre. (75)

La borrachera se le disipó, cuenta más adelante el relato, y huye del lugar. El cuento no hace sino repetir una antigua superstición ${ }^{18}$ de la pampa argentina, mediante la cual el séptimo hijo o hija, al no ser ungido por el sacramento bautismal, se convierte en lobizón ${ }^{19} \mathrm{O}$

${ }^{18}$ Las supersticiones, mitos y leyendas sobre el cuerpo (la sexualidad y la diferencia sexual) y, sobre todo, el malditismo de brujas, hechiceros y lobos investidos de un poder perversamente sexual, son asimilados por gran parte de la narrativa hispanoamericana. Bien de una manera sutil, por ejemplo, desde el universo hipersexualizado de lo femenino devorador como es el caso de la novela de Rómulo Gallegos, Doña Bárbara hasta, por ejemplo, el imaginario de la imbunchificación (perversión del cuerpo: desalojo de vísceras y suplantación de rellenos) que se observa en la obra de José Donoso, El obsceno pájaro de la noche.

${ }^{19}$ La imagen del Lobirón, según anuncian muchos estudios de los mitos y leyendas argentinos, es una superstición que tiene su origen en algunas formas orales recogidas en Europa. La superstición cuenta que el séptimo hijo varón al llegar a la adolescencia se transforma en lobizón los martes y los viernes por la noche (días álgidos en la pasión de Cristo). Los múltiples discursos proponen varias alternativas en las transformaciones de lo humano a lo animal y viceversa. También son varias las formas que el imaginario tiene para romper con el hechizo, casi todas vinculadas al ritual del bautismo. Bien bautizando al niño en siete iglesias diferentes, bien si es bautizado con el nombre de Benito o si el mayor de los siete hermanos funge de padrino. En Argentina, la costumbre de que el hermano mayor sea el padrino, se cambió más tarde por el padrinazgo presidencial. En la localidad del Coronel Pringles (donde transcurre la novela de Aira), se encontraron archivos en el que hacia 1907 se realizó el primer bautismo con el mencionado padrinazgo por parte del Presidente de la República. De hecho en 1973, el presidente Perón, legisló en forma de decreto, el 
bruja respectivamente. El cura se encuentra molesto por la asociación que establece la pareja con respecto a lo sobrenatural y la posibilidad de que al no bendecir el cuerpo de la criatura, se convierta en lobo. Por insistencia de los anfitriones y por lo complicado de la tormenta, el cura se queda a realizar su segunda cena, bendice la comida, pero el bautismo queda suspendido en el aire.

La segunda parte de la novela se narra veinte años después, también en una noche de invierno, ya no con un vendaval, sino como decíamos al principio, con un tenaz y arrasador diluvio. ${ }^{20}$ Transitando un territorio perdido e innombrable de la pampa, el cura viaja en un tren que descarrila debido a la terrible inundación que desmorona los caminos y puentes. Se genera una verdadera pesadilla de pérdidas, cuerpos destrozados, de heridos que claman auxilio. El cura se salva, saliendo por una abertura del tren y logrando nadar, no sin desfallecimiento y capturando una zorra: un objeto flotante, que lo hace llegar fatigadamente hasta un terraplén donde hay una casa, en lo alto, logra ponerse a resguardo de la lluvia que continúa con total intensidad. Una vez allí, grita, intenta pedir ayuda y otra vez, interno en la oscuridad de la casa abandonada, se da cuenta que no está solo y que hay alguien, probablemente echado en el suelo, durmiendo. Efectivamente, ese desconocido, aún con somnolencia, declara escuetamente: "Me refugié aquí cuando comenzó a llover" (101). El desconocido se percata que no está su caballo y que, probablemente, haya sido arrastrado río arriba por las fuerzas de las aguas. Aún así, el desconocido sale en su busca, con el peligro de los pozos, lodos y corrientes cada vez más evidente de las aguas, con el peligro de la oscuridad y de la impiedad de la tormenta. El

848, una costumbre generalizada ya en la cotidianidad. Según el decreto, los padres pueden optar por un padrinazgo moral del Presidente del Estado.

${ }^{20}$ Para Mircea Eliade el diluvio en todas las tradiciones sagradas se vincula a la idea de reabsorción de la humanidad en el agua (el agua como totalidad) y la implantación de una nueva era con una humanidad renovada. Dice: "Todas ellas demandan, pues, una concepción cíclica del cosmos y de la historia: una época queda abolida por la catástrofe y empieza una nueva era regida por 'hombres nuevos"” (220-221). 
cura no se queda solo por mucho rato, pues el desconocido vuelve con la cabeza cortada del caballo. Un caballo que no era suyo, y para evitar suspicacias de venta, deberá mostrar con esa prueba contundente que el caballo fue arrastrado por las aguas hasta un molino que le cortaría, al ras, la cabeza.

Ambos mantienen una conversación un tanto tirante porque, a pesar de que el desconocido es un pueblerino del lugar, no puede, pese a la insistencia del sacerdote, determinar en qué sitio están protegidos: "estos lugares no tienen nombre", están lejos y cerca de cualquier pueblo. Se trata otra vez, como en la primera parte, del crepitar de lo incierto. Los dos hombres permanecen sentados uno en frente del otro, callados. El cura se da cuenta de que el desconocido le muestra su perfil, abstraído en otras cosas. Le observa, de una manera reiterativa, y resultando que este hombre era no solamente muy joven, casi un niño, aunque con altura y fuerza, sino también un ser de infinita belleza. El rostro, los contornos y las facciones le recuerdan misteriosamente la iconografía de los ángeles: "El cuerpo era robusto, atlético. El rostro, muy bello, de rasgos perfectamente regulares como los de un ángel de la pintura; la barba de dos días no le quitaba su irradiación de hermosura, ni lo hacía hirsuto o cruel" (108).

El sacerdote, en su revisión, se mira también a sí mismo desnudo, sin las ropas que permanecen húmedas a su vera y se compara con "ese ángel" que aún lleva la ropa puesta, con la incomodidad que eso genera, pero sobre todo, porque no muestra las siluetas o ese cuerpo todo de "rara perfección". Los pensamientos del cura, lo conducen hacia la reflexión de la mirada, gran invocación de sus estudios de cine, pues, como comenta Echavarren, el religioso es atípico ya que muestra profundas inclinaciones por la fotografía y por el artificio del cine. Sabe mirar, detallando las formas imperceptibles, el detalle en un conjunto que produce fascinación (y el deseo) a quien contempla. Después de las lucubraciones cinematográficas, de las observaciones incisivas sobre el cuerpo del joven, ahora compañero de la desventura, inicia una conversación sobre la situación climática. El padre desea saber datos sobre el joven, y posteriormente, a propósito de su gusto por dormir en el suelo, 
confiesa que tiene veinte años y que es peón de campo. La pertenencia del caballo lleva la conversación hacia la figura de Isolina Marina, con quien el joven confiesa haber hecho teatro; el motivo de haberse dejado el teatro radica en que:

“...era una pérdida de tiempo y (cada) dos por tres tenía que disfrazarme de mujer". El cura asintió con melancolía: "Es el peor defecto de los folletines camperos que se dramatizan por aquí.". "Es ridículo". Estoy en un todo de acuerdo. Es abyecto, pornográfico. No me explico como una dama cultísima como Isolina, puede insistir con ese juego. (119)

El párroco recuerda que doña Isolina, a quien conocía previamente, le presentó a Victoria Ocampo y que además ésta poseía suntuosos trajes de un diseñador inglés del siglo XIx: Worth, quien vivió muchos años en París. Estos trajes que Isolina usaba para el teatro, los hacía planchar y remendar por las monjas. En cierta ocasión, siguió recordando el religioso, en un viaje que hizo a Pringles, se enteró que Isolina llevaba estos trajes a las monjitas quienes planchaban y acondicionaban los encajes con las planchas de hacer hostias: "El ligero matiz sacrílego se pasaba por alto, en virtud del entretenimiento y de la calidad sublime de la obra de arte" (120).

Con esa imagen se sutiliza lo que va caracterizando la narración de El bautismo: el sujeto de la enunciación introduce el motivo de travestismo del joven en el teatro de Isolina como consecuencia o resonancia del correlato mítico que, en el cuento folletinesco de los jóvenes campesinos disfrazados de mujer, reitera sus implicaciones en el sexo y la apariencia. El joven no se viste de mujer para no "dejarse violar" como la última "muchacha" de la superstición. Abandona el teatro porque le repugnaba el disfraz. Se dan, por consiguiente, interrelacionados, factores tematizados que hay que considerar en la narración; primero, que el joven no acepta con continuidad vestirse con los trajes de una moda suntuosa, esquemática y esencial que propone un rol o un tipo de mujer codificada, pues el travestismo como fingimiento, como simulación de la mujer, le re- 
sulta patético: "No creo que un hombre de verdad pueda confundirse con una mujer" (123).

En segundo lugar, que esos trajes de mujer, señalados por esa sutil herejía de su planchado, cuestionan el elemento religioso tomado como distancia, como culto. Y tercero, que no queriendo imitar a la mujer modélica, la de los trajes de Worth, se niega también a responder, con el pelo largo, como lo tiene, y sus facciones de ángel, al canon establecido para los hombres. Situado en un lugar intermedio, el personaje merodea el "ni" de las determinaciones sexuales. Debido a su profunda belleza y, a pesar de su vigor atlético o de los rasgos viriles como la barba, se erige ante nuestros ojos, por los ojos del narrador y del sacerdote, su presencia encantada como la de un ángel. Un perfume indescifrable que se volatiza ante una crítica representación eclesiástica. A pesar de ese brillo, el sacerdote denota la ausencia de narcisismo en sus palabras: no se sabe bello, lo que lo hace más hermoso todavía, ajeno a cualquier forma determinada por una posible autofascinación: "Uno se convence de lo que ve en el teatro. Uno quiere ver otra cosa. El secreto que oculta. Y el secreto es sagrado [...]. El secreto está infinitamente protegido. Los disfraces siempre están superpuestos. No hay posibilidades de atravesar esa muralla, sino con el salto arriesgado de la creencia" (123).

Esta cita marca el talante reflexivo sobre la identidad, la determinación y la nominación que sutilmente ha ido instalándose en la novela, pues el teatro -que ha abandonado este peón itinerantefunciona como una especie de mecanismo que pone en tensión sucesiva las identificaciones y los roles. El disfrazarse sucesivamente que niega la identidad estática, se propone como una destreza en la que el ser transita por múltiples identidades y máscaras. La identidad como sustancia inviolable y estática, como es signo en el catolicismo, por ejemplo, se resquebraja en el teatro de Isolina, pues los chicos debían representar papeles de chicas. Era mostrarse en escena desde el disfraz y el desbordamiento de capas y revestimientos sucesivos. Esto, el problema de la identidad y de su fuga estética, da pie para que Roberto Echavarren, crítico de la novela, reflexione: “¿Cuál es el 'fondo' de una identidad ¿Es hombre o mujer? Se trata de un rol 
precario, de una identificación en el hilo ilusorio de la vida. Pero detrás o delante, o cabe, se manifiesta lo extraño, lo indeciso, lo plural, esto y aquello [...] Si el significante tiembla no sabemos para qué lado se inclina" (Arte Andrógino 164).

Las creencias y pensamientos del cura, no resultan, strictu sensu, denominados por la modalidad de creencias y pensamientos católicos, pues el catolicismo distingue precisamente a los seres en esencias separadas, con formas y comportamientos, con apariencias y maneras que se hacen consustanciales y responsables, representativas de un sexo o de otro. Ciertos sectores en la historia y conformación de la cristiandad, como hemos visto con las teosofías, la mística o la estética euforizante, han dado, sin embargo, cierto privilegio a un imaginario de lo intermedio, el sexo de los ángeles, por ejemplo, en el que el dogma se hará de ojos ciegos ante esas tentativas, y mirará en la determinación de dos atributos, una restrictiva separación. Así, el joven de rasgos perfectos, de pelo largo y húmedo, exbibe una doble identidad. Sus significados huyen, se multiplican y el significado queda despojado, temblando, adherido a los amagos y los fetiches, a un recorrido vertiginoso de interpretaciones donde lo sexual y lo erótico posibilita contenidos. Por un lado, la imagen del dedo de resonancia fálica conjura el fetiche masculino: "El dedo brilló durante el tiempo que un relámpago se sostuvo inclinado en el cielo. Brilló, le pareció al cura. Algo más de lo que debía hacerlo naturalmente un dedo. No le había sorprendido que aquel joven desconocido fuera un robot de oro" (123).

Y por el otro, el contorno y el perfil que ofrecen el recogido de la húmeda cabellera imponen la ilusión de lo femenino... El joven peón responde así al sacerdote, de nuevo preocupado por la incomodidad de las ropas mojadas que llevaba: "Lo que más me molesta es el pelo”. “¿Te lo escurriste?” - pregunta a continuación el cura‘Sí, pero lo siento como un peso húmedo. Debería atármelo’ [...]. Con dos movimientos decididos hizo el nudo; el pelo le quedo tirante, con la 'cola' muy alta en la nuca. 'Así está mejor', comento" (124).

La forma angelical que muestra el peón lo coloca al margen de la distinción: todos los cuerpos en el cuerpo, todos los sexos en el 
sexo o tal vez ninguno de los sexos. Su figuración no se corresponde con las formas suspiradas y románticas de un imaginario angelical predecible. Este ángel de Aira tiene que ver más con un perfil concreto, preciso y visible, como algo que se desborda en su exhibición y que, no obstante, parece albergar un secreto indescriptible.

El clérigo y el peón siguen conversando hasta el momento álgido de los "reconocimientos". El religioso, al descubrirse como cura, le revela que fue párroco de un caserío, El pensamiento, al que el desconocido señala como su lugar de origen. Las asociaciones con personas y momentos precisos de su labor como párroco en este poblacho de la pampa y las respuestas acertadas del peón conducen, como en el teatro griego, hacia la fatalidad de la anagnórisis. El clérigo entra en crisis cuando descubre que este hermoso joven, que este ángel, es el hijo del vasco, aquél que una noche de vendaval suplicó junto a su mujer el bautismo de su hijo recién nacido, débil, enclenque y "monstruoso". De un zarpazo, este ángel que no tenía nombre, ese ser de hermosa figuración y con un estilo de vida itinerante, pasa del terreno de lo innombrado, "de los sin nombre", a lo nominativo; de la veleidad de lo incierto o lo indeterminado, a una identidad fija encerrada en el nombre y muere, de pronto, como la bestezuela de la primera parte de la novela.

...un minuto antes ese joven no era nadie, era un desconocido, un ángel. De pronto, resultaba ser el hijo de Mariezcurrena. El nombre imponía las cosas, y el mundo caía con espantosa regularidad. Los relámpagos se habían acabado casi todos. Eso también podía contribuir. El ritmo irregular de los resplandores había venido disimulando hasta entonces el peso opaco del tiempo. (136)

La identidad obtiene aquí el talante trágico, pues sumerge al sujeto en una certeza contundente, aleja la ilusión y sobreviene el desencanto, el despertar de la ceguera, la ruina, la muerte. "El cura superó el bajón hablando" (137). La ilusión del ángel era también la ilusión de un espacio más abierto, cuando en realidad estaban achicados en la casucha. La identificación sobreviene en la igualación, 
pues el brusco movimiento del sacerdote y del joven peón los acerca en un cara a cara, donde la distancia de lo otro pierde su perfume embriagante, pues en la dialéctica de aquellos náufragos nocturnos, de aquellos amparados por la noche, el sacerdote se hace poseedor del pensamiento, del concepto mientras el joven peón, articulado como ángel, era primeramente intuición, imagen, deseo y fatal y finalmente, nombre y pérdida del misterio. Agotados los temas de conversación, pues la identificación funcionó como un latigazo, como un despertar de la imagen que se sabe imagen equívoca, que ha revelado el artificio cinematográfico, ha paralizado el movimiento del imaginario y su fulgor decae y deviene predecible.

No sabríamos decir si el peón figurado como ángel en la mirada del cura se localiza fuera del territorio del cristianismo más riguroso o son las creencias "atípicas e inesperadas", las reflexiones éticas y estéticas del sacerdote las que lo sitúan al margen del dogma, como una subrepticia impugnación. El cura se deprime porque la imagen angelical del peón ha caído en la generalidad del nombre y la identificación, la estampa ambigua se ha precipitado y reducido a un simple género. Quizás la formación cinematográfica del sacerdote, aclara el narrador, hace que éste valore más el perfil, las formas ambiguas, el contorno que antecede al nombre, a una juventud despojada de determinación sexual, de un posible andrógino en el delirio de una noche incierta y diluviada.

Esa misma ambigüedad será el sustento de muchas de las obras de Juan Carlos Onetti, en las que la figura del ambiguo, de la "muchacha" y sus variaciones en sus novelas y cuentos, ${ }^{2}$ lejos de ser una preferencia real del autor, como ha increpado con suspicacia cierta crítica recalcitrante, es una imagen y motivo de deseo andrógino, de instancia erótica que también decae, muere en la fatalidad de

${ }^{21}$ Ver Onetti, "Historia del caballero..." 189-212. Este cuento en el que el personaje femenino parece detenido en la "virginidad alegórica" del embarazo y la fealdad grotesca, mientras que el caballero de la rosa, debido a su enorme belleza y ambigüedad, es objeto de fascinación de hombres y mujeres. En la novela El astillero de 1961 (Madrid, Cátedra, 1991), el viejo Larsen se coloca en la intersección del deseo irrealizado. Por un lado, rechaza al ambiguo adolescente que estaría dispuesto a brindarle ciertas 
algunos significados. En este sentido, caben algunas correspondencias, ya que el ángel de El bantismo pierde, de un plumazo, su condición plural, indeterminada, ambigua, de la misma manera que la imagen de la "muchacha" en la narrativa onettiana es asumida primero por ese deseo inconfesable de sus narradores, como una especie de tercer sexo, o mejor aún, en esa indeterminación: en un más allá del sexo. Piénsese en casos muy singulares como en la novela corta El pozo (1939), donde, según la visión del narrador, la mujer, tragada por los convenios, por la generalidad y los estereotipos va muriendo indefectiblemente, empeñadas en cumplir un programa de vida que les asigna un exterior, abandonando, también de pronto, esa maravillosa cualidad de la primera juventud. ${ }^{22}$

Otra correspondencia, que se desprende de la anterior, es el desplazamiento de la tensión erótica. Pues se diga o no, esa fascinación del sacerdote, que si bien no es fuertemente sexual desde el punto de vista de una probable consumación, tiene resonancias eróticas que posteriormente derivan en desencanto y depresión. El ángel, en el dominio del muchacho/muchacha, pierde su fuerza imantadora de deseo. A las mujeres "preñadas" de las narrativas de Onetti le sucede algo parecido. Pues el embarazo en novelas como La vida breve (1950), lejos de activar la ambigüedad del deseo eróti-

prestaciones, a su vez que Inés María, por el otro, se aleja de cualquier posibilidad de realización amorosa. Son dos formas inaccesibles y complementarias de vivir el deseo. En una novela posterior, Dejemos hablar al viento de 1979, el deseo global masculino/femenino de Medina hacia Seoane, se torna maldito, conjurado por la pérdida y el crimen.

22 "Pero la gente absurda y maravillosa no abunda; y las que lo son, es por poco tiempo, en la primera juventud. Después comienzan a aceptar y se pierden. He leído que la inteligencia de las mujeres termina de crecer a los veinte o veinticinco años. No sé nada de la inteligencia de las mujeres y tampoco me interesa. Pero el espíritu de las muchachas muere a esa edad más o menos. Pero muere siempre; terminan siendo todas iguales, con un sentido práctico bediondo, con sus necesidades materiales y un deseo ciego y oscuro de parir un hijo [...]. Y si uno se casa con una muchacha y un día se despierta al lado de una mujer, es posible que comprenda, sin asco, el alma de los violadores de niñas y el cariño baboso de los viejos que esperan con chocolatines en las esquinas de los liceos". (Onetti, Elpozo 20) 
co, lo descoyunta, lo desequilibra, se instala como una mentalidad en las mujeres adultas, ${ }^{23}$ ocasionando un descalabro en el juego simbólico que se establece a partir de las formas androginales de la primera juventud, en cuanto a las diferencias de los sexos. ${ }^{24}$

Decíamos de otra forma que la anagnórisis no rebasa la trascendencia y jalona los cuerpos hacia una realidad cotidiana, salvo por el hecho de que ahora cada uno de los personajes, desde sus posturas, uno en la reflexión y el otro en lo irracional, deben complementar una salida a su situación desesperada, ya que las aguas amenazan con arrasarlos. Así, han de idear una salvación fuera de los dominios de Dios.

Y si el cristianismo era la creencia. Lo era por ser el más completo e indudable sistema contra la creencia, contra el nacimiento casual, en la realidad, de la creencia. Ahora sólo le quedaba esperar la salvación, pero en eso habría una ambigüedad hasta el final. Sabía que si le hacía la pregunta al jo-

${ }^{23}$ En la crítica a la obra de Juan Carlos Onetti, ha habido una primacía de estudios de los aspectos existenciales, de la demoledora orfandad del ser, de sus demonios o del deterioro moral de los personajes que pueblan el universo onettiano. El relevo de la sensualidad por la maternidad, el funcionamiento erótico de la mirada narrativa ha derivado en polémicas de tipo moral y de censura, ignorándose que, por ejemplo, la visión profundamente laica y no fecundante de sus narradores y personajes confirman y conforman un destino distinto de las mujeres, en la que la maternidad es sólo una opción. El mismo Roberto Echavarren señala un camino de lectura: "No hay nada intrínseco en el rol de la madre, no hay consecuencias inevitables para siempre y para todos por el hecho de ser madre. Lo que el protagonista de Onetti rechaza es el peso inercial de la tradición cristiana, que consagra los sexos como esencias, siendo esencia para la mujer su función de madre: la única justificación del sexo es procrear. Como si esto fuera poco, jerarquiza la procreación por encima del sexo, transformando a la madre glorificada en 'virgen', ya que al tener hijos lava los pecados de la sensualidad” (Arte Andrógino 146).

24 "Está loca, no tiene derecho a esto, a convertirse en una ruina grotesca [...]. Porque así como en el traje recto y flojo es el uniforme de todas las inminentes madres del mundo, el pequeño sombrero sin adorno, ceñido como un caso, proclama la resolución de la pureza, el desprecio por las posibilidades sensuales de la vida, su adhesión al debery a la soberbia estupidez" (Onetti, La vida breve 215). Las cursivas son nuestras. 
ven como una adivinanza, le respondería: la salvación es: que pase por aquí un paquebote. El mencionaría a Dios. El otro diría que pase por aquí Dios, nadando en estilo crawl.

Dios tenía estilo. La salvación no. La muerte tampoco. Eran la clase de cosas que ocurren cuando no hay tiempo para observarlas. (148-149)

El narrador que nos hace saber la perspectiva transformada del cura con respecto a la salvación, nos presenta un punto de vista, sugiere Echavarren (ver Arte Andrógino 147), anómalo con respecto al sistema de la fe y de la salvación como principal motor del cristianismo. Si el cristianismo impone la fe bajo los dominios del dogma, en forma de esencia y generalidad incuestionable, el sacerdote, al contrario, observa en lo "distinto", lo "otro" de la imagen angelical, de la impronta ambigua del peón, una activación imaginaria, y reflexiona (cabría decir, que se deja "seducir") gracias a esa imagen. El estilo, que nos presenta el ángel, es una disonancia de la apariencia impuesta, de las formas jerarquizadas, una multiplicidad de superficies, donde el cristianismo, reflexiona el párroco, se aventura como una aniquilación del estilo por lo que la imaginería escatológica, herética y alquímica sólo resta y ondea como sustrato de contaminación de lo irrevocable, de lo único.

Al final de la novela, lo ambiguo se determina, y lo inestablemente fetiche deja de irradiar sus intermitencias, sus brillos, sus reminiscencias de lo otro. El peón adquirió un vuelo entretenido y de estilo, un cuerpo angelical ante la mirada del cura. Adquirió la categoría infusa del ángel: una zona, un cuerpo intermedio, liminar como la bestezuela falsamente voladora del comienzo de la novela, pero como ella, al ser identificada, trasferida a un acto de denominación, ${ }^{25}$ a lo definido, a la certeza, su presencia se encumbra en las limitaciones de la identidad, de las esencias, de las formas jerárquicas, de la muerte simbólica y, en definitiva, de la

${ }^{25}$ Para el análisis de la relación entre el nombre propio y muerte, véase el trabajo sobre la denominación de Derrida. 
muerte del deseo. Pierde, sin lugar a dudas, el estatuto de deseo en la imagen, el estatuto de cuerpo celestial. Deriva fotograma caído.

El joven no era otra cosa de lo que en realidad era: un muchacho ignorante al que le había sorprendido la lluvia sobre un caballo prestado. Ni ángel ni demonio, en la fría luz de la aurora: un joven alto, bien formado, de rasgos lindos, con la belleza mística de una inocencia presa de todos los engaños. Un Apolo, sí, pero como tantos Apolos de veinte años que se encuentran en el campo, con la tersura infantil todavía en las mejillas, en la frente, en los brazos, un niño grande desarrollado por la vida sana y lo aires puros. Un alma limpia a la que infectaba la mentira, pero qué otra cosa esperar. Con la edad le crecería la barriga y se le arquearían las piernas; la vida brutal y monótona le haría estúpida la cara. Un hombre, en fin, un hombre, al que habría podido darle su bendición en esa hora pálida, en el blanco de la mañana. (153-54) ${ }^{26}$

Esa misma "vida brutal" dice, casi con resentimiento el personaje, será un síntoma del despertar al significante equivoco, que inaugura una distancia: "Ni ángel ni demonio" entre la apariencia andrógina y su deseo, sostenida, decíamos, por el colmo de la juventud frente a las formas reales de la adultez. El sacerdote sabe, como adulto y hombre de fe, que se encuentra excluido para siempre de una visión de ese círculo andrógino. Esa exclusión será compensada con la certeza de que ese joven ambiguo perderá, con el tiempo, todo vestigio de angelitud, de indeterminación perfecta.

Esta formulación encuentra, una vez más, su vinculación con uno de los cuentos de Juan Carlos Onetti, "Bienvenido, Bob”, en la

${ }^{26}$ César Aira introduce ya en la culminación de la novela la risotada de la ironía, pues no solamente pierde, de alguna manera, su encanto con los efectos de la "identificación", sino que también a este terrible despertar se le añade otro, el de las apreciaciones políticas: el ángel, el que dejó de serlo, se confiesa idólatra del peronismo y la imagen parece estrellarse aún más. "'Siempre seré peronista’. ‘Eso es un capricho, una manía!' 'Como usted quiera, pero es lo que yo pienso'. 'No perdóname que te contradiga, pero todo lo contrario, si pensaras..." (Aira 153). 
que el narrador, en su fuero interno y vengativo, da recibimiento "al tenebroso y maloliente mundo de los adultos" al que antes, hubiera podido ser su bello y delicado ${ }^{27}$ cuñado, si éste no se hubiese opuesto de manera contumaz a la relación con Inés. Ha dejado de ser Bob y se ha convertido en Roberto. Ha dejado de ser el cuñado rubio, de ojos azules, ambiguo e idéntico a su hermana, convirtiéndose ahora en un compañero de café y cervezas. Queda suspendido en un deseo vuelto ahora ironía y podredumbre. ${ }^{28}$

Finalmente, tanto los personajes de Onetti como éstos de César Aira, recuperan abrupta y terriblemente, bien por la llegada de la adultez o por la revelación de las ambigüedades, una humanidad que permanecía descarrilada por las fantasmagorías de la androginia. El ángel se convertirá, a fuerza de desmantelar la incógnita, en un hombre corriente, violentando la posibilidad estética, el milagro casi, de citar cuerpos celestiales en un espacio que no sea el que irreductiblemente se asigna por la mediación de lo imaginario y del deseo.

27 'En aquel tiempo, Bob era muy parecido a Inés; podía haber algo de ella en su cara, a través del salón del club, y acaso alguna noche lo haya mirado como la miraba a ella [...]. Pero casi siempre prefería olvidar los ojos de Bob y me sentaba de espaldas a él y miraba la boca de los que hablaban en mi mesa, a veces callado y triste para que él supiera que había en mí algo más que aquello por lo que había juzgado, algo próximo a él; a veces me ayudaba con unas copas y pensaba 'querido Bob, andá a contárselo a tu hermanita', mientras acariciaba las manos de las muchachas que estaban sentadas en mi mesa o estiraba una teoría sobre cualquier cosa, para que ellas rieran y Bob lo oyera." (Onetti, Cuentos completos 125-126)

28 "Ahora hace cerca de un año que veo a Bob casi diariamente, en mismo café, rodeado de la misma gente. Cuando nos presentaron -hoy se llama Robertocomprendí que el pasado no tiene tiempo y el ayer se junta allí con la fecha de diez años atrás. Algún gastado rastro de Inés había en su cara, y un movimiento en la boca de Bob alcanzó para que yo volviera a ver el alargado cuerpo de la muchacha, sus calmosos y desenvueltos pasos, y para que los mismos inalterados ojos azules volvieran a mirarme bajo un flojo peinado que cruzaba y sujetaba una cinta roja [...]. Nadie amó a mujer alguna con la fuerza que yo amo su ruindad, su definitiva manera de estar hundido en la sucia vida de los hombres." (Onetti, Cuentos completos 130-131) 


\section{Obras citadas}

Aira, César. El bautismo. Buenos Aires: Grupo Editor Latinoamericano, 1991.

Arenas, Reinaldo. Arturo, la estrella más brillante. Barcelona: Montesinos, 1984.

Chalbaud, Román. "Los ángeles terribles." En: Teatro II. Prol. y notas Marita King. Caracas: Monte Ávila Editores, 1992.

Contreras, Sandra. "Las vueltas de César Aira." Actual (Mérida, Universidad de los Andes) 33 (1996): 91-110.

Derrida, Jacques. Memorias para Paul de Man. Trad. Carlos Gardini. Barcelona: Gedisa, 1989.

. "Políticas del nombre propio." En su libro Filosofía como institución. Trad. Ana Azumendi. Barcelona: Juan Granica Ediciones, 1984.

Echavarren, Roberto. Ave roc. Montevideo: Grafitti, 1994.

. "El ángel fuera de la Iglesia: El bautismo." En su libro: Arte andrógino: estilo versus moda en un siglo corto. Montevideo: Ediciones Brecha, 1997.

Eliade, Mircea. "Las aguas y el simbolismo acuático." En su libro Tratado de historia de las religiones. Trad. A. Medinaveitia. Madrid: Cristiandad, 1980.

Foucault, Michel. "Les anormaux." En su libro Resume des cours (1970-1982). Paris: Jullimard, 1989. 45-56.

. Historia de la sexualidad. I: La voluntad de saber. Trad. Ulises Guiñazú. 1a. ed. Madrid: Siglo XXI, 1992.

Onetti, Juan Carlos. El astillero. Madrid: Mondadori, 1991. - Dejemos hablar al viento. Madrid: Mondadori, 1991.

. Elpozo. En: Cinco novelas cortas. 2a. ed. Caracas: Monte Ávila Editores, 1993.

"Historia del caballero de la rosa y de la Virgen encinta que vino de Liliput." En su libro Cuentos completos. Prol. Antonio Muñoz Molina. Madrid: Alfaguara, 1994.

Puig, Manuel. Pubis angelical. 3a. ed. Buenos Aires: Seix Barral, 1980. Quintero, Ednodio. "Cesar Aira: una trilogía imaginaria." Actual (Mérida, Universidad de los Andes) 33 (1996): 81-89. 
Rojas Guardia, Armando. "Qohelet y la moral provisional. El principio de incertidumbre." En: Diario Merideño. Mérida: Ediciones de la Revista Solar, 1990.

Swedenborg, Inmanuel. "Del cielo y el infierno. El cielo y sus maravillas. El infierno." En: Antología. Trad. Jesús Imirizaldu. Madrid: Editora Nacional, 1977.

Vázquez García, Francisco. "La imposible fusión. Claves para una genealogía del cuerpo andrógino." En: Variaciones sobre el cuerpo. Eds. Diego Romero de Solís, Juan Bosco Díaz-Urmeneta Muñoz y Jorge López Lloret. Sevilla: Ediciones de la Universidad de Sevilla, 1999. 165-183. 